\title{
Las fronteras de la muerte en Perú: conceptualización y análisis
}

Recibido: 22.07 .18

Aprobado: 21.09.18
María del Carmen García Escudero

Universidad Autónoma del Estado de Hidalgo, México.

Área Académica de Historia y Antropología.

mariadelcarmen_garcia@uaeh.edu.mx

\begin{abstract}
RESUMEN
El presente artículo es un análisis del contacto de dos culturas y su forma de percibir la muerte: lo que hemos denominado fronteras. Digo fronteras, porque en muchos casos casi son percepciones sutiles entre una cultura y la otra, una frontera nítida, en otros casos podemos observar adaptaciones o simplificaciones de ambos contextos para una mejor convivencia, y en otras opciones son fronteras inquebrantables, son omisiones de una cultura, la frontera con la historia real y la historia contada, adaptada o inventada. Para el análisis del período precolonial, haremos una pequeña mención, pues no es el objeto del presente artículo, al método de investigación que utilizamos hace años: estudio de la dimensionalidad. El artículo es una novedosa introducción sobre el momento en el cual la muerte forma parte no solo de un concepto que hay que adoctrinar o cambiar, sino, como veremos, la muerte, es la representación de una comunidad, su sustento y equilibrio, la evangelización, teniendo en cuenta el grado que quería alcanzar, no podía extirpar un aspecto que no se puede conceptualizar, sino que es una percepción mucho más compleja que mostraremos.
\end{abstract}

Palabras clave: muerte; evangelización; comunidad; fronteras.

\section{The boundaries of death in Peru: conceptualization and analysis}

\begin{abstract}
This article is an analysis of the contact of two cultures and their way of perceiving Death: what we have termed borders. I say borders, because in many cases they are almost subtle perceptions between one culture and the other, a clear border, in other cases we can observe adaptations or simplifications of both contexts for a better coexistence, and in other options are unbreakable borders, are omissions of a culture, the border with real history and history told, adapted, or invented. For the analysis, we introduce a new working method that has allowed us, for the studies of the precolonial central Andean region, to investigate data that until now were not taken into account: it has been called dimensionality study. The article is a novel introduction about the moment in which Death forms part of not only a concept to be indoctrinated or changed, but, as we shall see, Death is the representation of a community, its sustenance and balance, evangelization, taking into account the degree he wanted to achieve, could not remove an aspect that cannot be conceptualized, but is a much more complex perception that we will show.
\end{abstract}

KEY wORDs: Death; evangelization; community; borders. 


\section{Introducción}

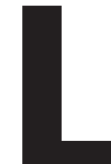

a muerte, temida y adorada a lo largo de la historia de la humanidad, es clave en las investigaciones de todas las áreas, la medicina quiere saber los procesos de la muerte e intentar paliar, en nuestra cultura, las implicaciones que tiene la muerte; como el dolor o alargar la vida. En sociología las estadísticas de muertos en un país determinan la vida, la sociedad, y el contexto del mismo. Las investigaciones sobre el universo se interesan por la muerte de las estrellas y cómo repercute a su vez en nuestras vidas; la neurociencia ha mostrado que las neuronas no mueren, que envejecemos y podemos seguir aprendiendo, investigando, desarrollando en nuestro entorno actividad. Para la sociedad occidental la vejez es dejar de ser, pero, para otros contextos, en otras culturas, y en otros períodos de la historia, el más anciano, tenía un papel relevante dentro de la comunidad y su desarrollo óptimo; como es el caso del Perú prehispánico y el desarrollo de oficios importantes para el equilibrio y desarrollo de la comunidad. En nuestra sociedad, desgraciadamente, se genera un latente e inquietante proceso de decadencia y aislamiento. Digamos, que podríamos hacer un artículo sobre cada área que estudia la muerte. En nuestro caso, desde una perspectiva multidisciplinar, hemos realizado el esfuerzo, digo esfuerzo porque realmente es muy complejo el análisis, de analizar las fronteras de la muerte en el período colonial: el momento en el que se unieron formas de concebir la muerte entre dos culturas disímiles. A diferencia de nuestra cultura, que le da un papel, a la muerte, realmente definitivo para el individuo y entorno familiar, para la cultura de la región centro andina, es relevante, pero es indivisible a la vida. Para hablar de muerte, se debe conocer la percepción de la vida, de comunidad, la geografía espacial, la geografía anímica humana, y relacionar el espacio- tiempo con la construcción del ser. Podríamos anticipar que el antiguo Perú era el lugar dónde no se moría; por varios aspectos que iremos retomando a lo largo del artículo.

\section{Aspectos generales de la evangelización}

Para analizar esa frontera, ese momento en el cual se delimitan y se confrontan conceptos y culturas se realizará un pequeño análisis de la introducción del concepto de muerte que predicaba la evangelización en sus primeros momentos. Este análisis nos permitirá, en primer lugar, observar qué y cómo se expandía el concepto de morten, y cómo se respondió por parte de las poblaciones que habitaban el largo y extenso Tahuantinsuyu. En segundo lugar, se mostrará que la muerte no puede ser analizada como un concepto: tiene múltiples dimensiones que se tienen que tratar. Digamos que la muerte, al final, es una imagen del otro y su cultura, por lo tanto, es complejo el análisis por la dificultad de visualizar aspectos divergentes que tienen la misma coyuntura: el difunto y los «trámites pos mortem $»^{1}$.

Las primeras órdenes religiosas ${ }^{2}$ que fueron a evangelizar la zona que abarcaba el Tahuantinsuyu, a diferencia de Nueva España ${ }^{3}$, fueron, por un lado, la orden de los Hermanos Predicadores, Dominicos, por otro lado la orden de Nuestra Señora de la Merced, Mercedarios, que no era una orden mendicante, la orden de San Agustín, agustinos, y la orden de San Francisco de Asís, los franciscanos. Y finalmente, la Compañía de Jesús, y el sistema de reducciones.

Los párrocos de indios ${ }^{4}$ vinieron como enviados especiales de la corona española para la evangelización de los nuevos territorios conquistados por ésta. La tarea no era nueva para una iglesia que había luchado, junto a la monarquía católica, en la expulsión de los musulmanes; además de vivir en plena guerra ideológica con la expansión del protestantismo.

1 Existe mucha bibliografía sobre la evangelización, nosotros nos centraremos en el concepto de muerte que quiere introducir la evangelización. No mostraremos toda la bibliografía consultada, pues, como se puede observar, nos hemos centrado en las fuentes primarias, en recopilar información de primera mano y no seguir repitiendo lo descrito tanto en crónicas como en otros libros sobre el tema. También es sensato aclarar que estamos intentado ver la frontera de la muerte, pero con el punto de vista del «otro» de la cosmovisión andina. No es un artículo sobre evangelización.

2 Esta parte parecerá larga, pero, realmente tenemos que conocer la evangelización, métodos y objetivos, si queremos saber cómo se confrontaron ambas culturas.

3 Que fueron los franciscanos, y su intento de hacer un Tercer Reino en Nueva Espańa. Estaba garantizado en el Nuevo Mundo, pues sus pobladores tenían unas cualidades que garantizaban la posesión del reino de los cielos: eran pobres, sencillos, puros. Los principales centros de formación de los que salían los misioneros estaban, en Valladolid, en el colegio de San Gregorio, y en Salamanca, en el convento de San Esteban.

4 Los llamamos doctrineros, porque su deber era enseñar la doctrina cristiana a los pobladores de las Indias, normalmente los curas que administran la fe en sus parroquias, e iglesias, se llaman párrocos, y doctrineros los que se encargan de los nativos del Nuevo Mundo. Así, durante el trabajo, los llamaremos, o bien doctrineros, o bien párrocos de indios. 
Casi toda la información que hemos revisado, de esta primera fase de la evangelización, procede o bien de militares o bien de curas, por lo que será, podríamos decir, una información, en cierta medida, que representa dos tipo de guerras: la religiosa y la expansiva-territorial. Habiendo, como veremos, casos excepcionales entre los cronistas al servicio de la Corona española, como es el caso del Lic. Polo de Ondegardo.

Los primeros contactos del Inca con Fray Vicente de Valverde han sido numerosamente relatados: $" Y$ allí le trató el Padre F. Vicente el fin e intención de su venida a este reino, y cómo venía de parte del Papa y del Emperador a darle noticia de cosas importantísimas para el bien de su alma y salvación della» [...] "Arrojó el libro en el suelo (la Biblia) con desdén, a lo cual dando voces el padre Fr. Vicente de Valverde y diciendo: ¡cristianos, los evangelios de Dios por tierra!» (Murúa. 2001:197-200).

El Inca tuvo que renunciar a sus creencias para no morir en la hoguera. En ese justo momento de la historia, la muerte, sus rituales, destinos, ubicación y seres relacionados con ésta, cobran gran interés porque los párrocos de indios verán en éstos las múltiples caras del Demonio. Fue un largo período muy conflictivo para ambas formas de percibir el mundo.

[...] y engańados por el demonio cumplían su mandamiento, porque él les hacía entender (según ellos dicen) que después de muertos habían de resucitar en otra parte que les tenía aparejada, adonde habían de comer y beber en voluntad [...] tomaba la figura [el Demonio] de alguno de los principales que era muerto, y mostrandose con su propia figura y talle tal cual él tuvo en el mundo, con aparencia del servicio y ornamento, hacía entenderles que estaba en otro reino alegre y apacible, de manera que allí lo vían (Cieza de León, 2005: 252).

Los párrocos de indios tenían, para la salvación de la población, unos objetivos definidos como «urgentes»: el bautismo en masa, la confirmación, la extremaunción, la eucaristía y el matrimonio católico. La primera urgencia era el bautismo para que la población "pagana» no muriese en pecado; así se comienza con los bautismos en masa. El bautismo, además de las otras medidas urgentes, fueron difíciles de administrar, en muchos casos por la incompren- sión y en otros por el simple miedo a los métodos usados por algunos de los doctrineros; como fueron las penitencias corporales, etc. Básicamente, uno de los problemas fue que los indígenas no entendían el concepto de "pecado o falta cristina $»^{3}$. Algunos de estos problemas, por ejemplo, fue que en un principio la evangelización se realizaba en latín: "...que todos los yndios sepan la doctrina cristiana en latin a rresultado de aqui que los que la sabian en rromance la an olvidado y nunca acaban de deprenderla en latin que como es lengua mas rremota y menos usada...» (A.G.I, Patronato190, R.42 /1/1.) Esta primera fase destaca por la falta de comunicación, pues, los párrocos no conocían las lenguas nativas, y los nativos desconocían el latín. Este aspecto, la imagen de dos personas que no se entienden, pero que se deben de escuchar, es tan trágico, como cómico.

La falta de comunicación, los castigos corporales, y las separaciones territoriales de comunidades, como veremos, hicieron que se tomasen medidas. Atendiendo a que la población no asistía a la iglesia, por diferentes motivos, miedo, abandono de las parroquias, etc. Se determinaron días obligatorios: los domingos y los días de cuaresma.

La incomprensión de la lengua, los castigos físicos, y el nuevo orden ético, atendiendo a los pecados católicos, y según la gravedad de éstos, resultó realmente caótico para la convivencia. Esto propició la huida de muchas de las poblaciones hacia las regiones de la selva. La vida cotidiana del nativo era paganismo e idolatría:

[...] para conservar su disciplina eclesiástica y religión había que usar necesariamente una pena externa y corporal,...los crímenes tan terribles de idolatría, apostasía, superstición pagana y los sacrilegios cometidos pueden y deben castigar a los indios. Además, hay que corregir aquellos pecados menores como son la omisión voluntaria de la misa o de la catequesis y también los vicios que les son tan familiares como la ebriedad y el concubinato (Lisi, 1990:23).

Posteriormente, se determinó que para una mejor comprensión de la fe cristiana los doctrineros tenían que seguir una mínima preparación ${ }^{5}$, que hiciese

5 Después de la reforma del Cardenal Cisneros ser doctrinero será condición indispensable una mayor preparación de los misioneros, tendrán que saber, como requisito indispensable para la transmisión 
mejor el entendimiento entre ambas culturas. Si un párroco de indios confesaba a un nativo, pero no entendía lo que le decía, había un grave problema de comunicación, «pues no es buen juez quien juzga lo que ignora" (Lisi, 1990: 135).Los doctrineros tenían que velar por las almas de los naturales, para eso era necesario una serie de requisitos que tenían que cumplir, «han de tener en cuidar de la salud de sus ovejas» (Peña de Montenegro, 1995:77)

Para los párrocos de indios estas tierras vivían bajo la idolatría enmascarada por el Maligno, ellos eran los encargados de extirparla para la salvación de sus almas, de su «rebaño». Es, a través de estas campañas contra la idolatría (Millones, como mejor se puede observar y analizar el concepto de muerte y sus rituales; además de otras fuentes de información (Millones, 1989 y 1997). En 1583 el padre José de Acosta, encargado de extirpar la idolatría, junto a otros doctrineros y funcionarios reales, escribió sobre la idolatría lo siguiente: «Esa peste es el mayor de todos los males [...] no hay ningún otro veneno que una vez bebido, penetre más íntimamente en las entrańas». Posteriormente, en 1771, Peña de Montenegro, escribió lo siguiente al respecto: «Esta mala semilla echó tan hondas raíces en los indios, que perece se hizo carne y sangre con ellos. Conque viene a ser que, aunque ha ciento y treinta y cinco años que tienen predicadores, maestros y curas que pretenden sacarlos de sus errores, no han podido borrarlo de sus corazones» (Peña de Montenegro, LII, 1995:460) Como veremos, esta es una de las muestras de las fronteras que había respecto a los cultos precoloniales, la muerte, el culto a los antepasados, determinaba a la comunidad, su sustento, su desarrollo y perpetuidad temporal. Por lo tanto, un cambio en los rituales comprendía un cambio en la propia comunidad y su desarrollo, de esta forma, no son simples fronteras conceptuales, sino barreras culturales que no se pueden cambiar mediante el adoctrinamiento.

Para los párrocos de indios los ídolos eran los intermediarios a través de los cuales se podía hablar con el Maligno. Los primeros doctrineros hablan de

de las Sagradas Escrituras, la lengua autóctona. Como ejemplo más notable tenemos las cartillas que hizo en lengua quechua el padre Fray Domingo de Santo Tomás, «... porque el oficio de doctrinero es enseñar predicando la ley de Dios» (Peña Montenegro, 1995: 119) Los principales centros de formación de misioneros fueron el colegio de San Gregorio, en Valladolid y el convento de San Esteban, Salamanca. este «mal» como algo imposible de extirpar debido a la fuerte vinculación de los pueblos con sus huacas y demás formas de adoración "pagana». Estas huacas, como veremos, en su mayoría se relacionan con ubicaciones del paisaje, indicadas por el sistema de ceques, y conforman un complejo sistema de ubicación geografía relacionada con la muerte; entre otros muchos aspectos de la sociedad inca. Realmente entre las huacas familiares, los difuntos, las cosechas y la comunidad existía una relación compleja, por ejemplo P. Arriaga escribió lo siguiente sobre los datos cuantitativos realizados en las visitas:

Son cinco mil seiscientos y noventa y quatro, personas las que se an confessado, seiscientos y setenta y nueve, ministros de idolatría, los que se an descubierto, y penitenciado por tales, seyscientos, y tres Huacas principales, que se les an quitado, $y$ tres mil quatro cientos y diez y ocho Conopas, quarenta y cinco Mamazaras ${ }^{6}$, y otras tantas Conopas, ciento, y ochenta y nueve Huancas (estos son diferentes de las Huacas) seyscientos y diez y siete Malquis, y los Brujos que se castigaron, en los llanos sesenta y tres, las cunas, que se quemaron, trescientas y cinqüenta, y siete, y quatrocientos y setenta, $y$ siete cuerpos hurtados de la Iglesia, y no se an contado, muchos cuerpos Chacpas, ni Chuchos, que también reverencian, y que los guardan en sus casas, ni los Pactos, ni Axomamas, ni Micsazara, ni Huantayzara, ni Huayriguazara, ni otras cosas, en que tienen mil supersticiones, que todas se an quemado los quales explicaremos en los capítulos siguientes. Los pueblos donde se hallaron todas estas cosas fueron treinta y vno, algunos dellos muy pe-

$6 \quad$ Las mazorcas de maíz que nacían juntas, zaramama, eran las más veneradas. Éstas no fueron huacas, ni conopas sino objetos sagrados. El concepto por el cual se concibió que los objetos dobles fueran sagrados nos muestra la gran expectación que debió acontecer un parto de gemelos. Suponemos, como muestran las informaciones de Pablo José de Arriaga sobre la penitencia y ayunos de los padres, que en la comunidad el nacimiento de nińos gemelos producía un gran temor. Estos fueron percibidos como entidades sagradas, cargadas de poderes sobrenaturales y predestinados a ofrecerse como mediadores con las divinidades. Además, hemos percibido el gran temor que existía entre la comunidad, la importancia de los dichos curi, pues durante las visitas de extirpación de idolatría los familiares los escondían de los curas, y no querían bautizarlos, pues eran entidades sobrenaturales en contacto con aquellas divinidades que los párrocos de indios destruían. Pero, sobre todo, en la relación de reciprocidad se temía el castigo de las deidades. En la actualidad el viento del feto, es un viento que sopla desde el lugar del entierro de un feto abortado o una placenta sin bautizo, «desprovistos de la sal cristiana del bautizo, se vuelven nińos desnudos o duendes, que matan a su madre: retorna al vientre a comer sangre y siguen devorando hasta consumir el corazón» (Platt, 2002: 34). 
queños, quatro de ellos avía visitado tres años antes el Dotor Don Plácido Antolínez, siendo su Cura, por comissión particular del Señor Arçobispo, y les sacó, y quemó muchas Huacas, y Conopas, aunque escondieron no pocas. Hallose en el común del pueblo mucha emienda después de primera visita, aunque no faltaron algunas reincidencias, especialmente de parte de los Hechizeros (Arriaga, 1968: 17).

Como se puede observar el número de huacas familiares, de cultos de la comunidad son abrumadores, sin contar aquellos que se escondieron, por ejemplo. Nuestros estudios, viendo datos como éstos datos, realmente son superficiales, genéricos: 679 hechiceros, 603 huacas principales, las cunas que se quemaron, los cuerpos de los difuntos, etc. Esta contabilidad, habla, primero, del gran número de huacas que se tenían, del importante papel de los "hechiceros», del culto a los antepasados y de la importancia del nacimiento. En las visitas, se quemaban las cunas porque se dieron cuenta que había muchos rituales entorno al nacimiento y realización de la cuna: era como un útero que cuidaba al bebé. Este entramado de información cuantitativa muestra la percepción de vida y muerte y su relación con la comunidad. La doctrina no podía llegar a una construcción social, compleja, antigua y que implicaba diversos niveles, todos ellos conectados, que sustentaban las comunidades.

El largo, extenso y entramado territorio del Tahuantinsuyu implicaba que no se pudiese acceder a poblaciones remotas para poder llevar los Evangelios. Posteriormente, las reformas del virrey Francisco de Toledo propusieron reducir a los indios en pueblos controlados por los españoles. Estas reducciones facilitarían el trabajo de los doctrineros al estar los indios controlados por las autoridades españolas. Los curacas, que eran los representantes de los ayllus, los «hechiceros», que eran los guardianes de la salud y bien estar, cada uno en su disciplina y género, y los quipucamayoc, que eran los encargados de guardar y conservar la memoria, fueron los más perseguidos por los curas doctrineros porque eran los intermediarios entre ambas sociedades. Cada uno de ellos era una amenaza para la colonia. «En algunas provincias no habia ni templo ni casa de adoración, solo tenían en cada pueblo dos o tres indos ancianos que hablaban del demonio, y a estos veneraban mucho por las respuestas que les davan. Creían algo de la inmorta- lidad del alma que en quanto la tierra produçe y engendra no conoçían concurso de Dios sino conoçían causa prima y total a la Naturaleza. Algunos caziques usavan tener a sus puertas unas tablas y en ellas esculpidas o pintadas algunas figuras de Animales para que las adorase el Pueblo que se socoriesse de ellas en las necesidades apuradas de los campos...» (De la Cruz. 1653:p.42.v.Mss.2450, B.N.M).

Por ejemplo, para intentar extirpar las antiguas creencias del territorio inca, y facilitar la expansión de los evangelios, se encerró a los principales ministros de los ritos idolátricos. Los hechiceros fueron confinados en lugares especiales, con la única excepción de abandono de este encierro para ir a la Iglesia a oír los Santos Sacramentos "Pónganles una guarda o dos, para que no los dejen salir a parte ninguna, y los domingos y días de doctrina, haga los lleven juntos a la Iglesia y, oída Misa y doctrina, vuelvan a la casa» (Murúa, 2001:443).

Los hechiceros fueron confinados para cortar la trasmisión cultural, pues, la cultura precolonial andina tenía sus cimientos en ésta: las platas medicinales, los quipus, las enfermedades y su diagnóstico, el tiempo y la cosecha, etc. A su vez, las nuevas generaciones también fueron aisladas, y apenas conocieron su entorno cultural por nacer en una sociedad diferente a la de sus antepasados. Estaban controladas para que no tuviesen contacto con sus familiares y detener la memoria histórico-cultural de éstas, «...y esten los nińos sin comunicación de sus padres desde la edad de 4 o 5 ańos hasta los 12 donde se les muestra por los sacerdotes la necesidad para que en ellos se funde e imprima nuestra santa fe catolica y desta suerte en tiempo de veynte ańos seran, y a los viejos muertos y los niños adultos sus ceremonias olvidadas y las de cristianos recibidas...» (A.G.I., Quito, 82, N.6/1/1. Recto). ${ }^{7}$

7 La memoria y la muerte están relacionadas íntimamente en la cosmovisión prehispánica, olvidar, es similar a la muerte, olvidar a los difuntos, a sus dioses, etc. Por ejemplo, Hernando de Santillán observó que: «...Cuando caían malos, en aquel lugar [la sierra], decían que la tierra estaba enojada y derramaban chicha y quemaban ropa para aplacarla..." (De Santillán, Hernando de; 1968:27). Si se olvidaba la relación que se poseía con la Madre Naturaleza se creaba una desmejora que afecta no sólo al individuo sino también a la comunidad, a la esencia de lo circundante. Esta relación de reciprocidad se mantiene hasta nuestros días, al respecto el médico tradicional Alberto Camaqui nos explicaba lo siguiente: «...todo está relacionado, hay una reciprocidad todos, tenemos los granizos, los fenómenos, aquí [arriba] los protectores cuando nuestra gente no se acuerda de todo esto pueden enviarnos este mal, pueden pedir. La gente tiene sus 
La iglesia introdujo un sistemático recuento de tasas obligatorias, al respecto, cabe destacar, que la salvación de los difuntos se facilitaría mediante el pago económico: «...diesmos y primas...que en punto de Dios se les exigen para cura dos reales por los oleos, ocho reales por las velasiones y seis reales y medio de las annas. De cofradias nueve reales los casados y cuatro reales y medio los solteros. Por entierros de parbulos a doce reales. Por los de grandes a trece...» (A.G.N, D.11/ hoja 705 recto). El neófito, ante el valor económico que había cobrado la muerte, podía encontrarse con el problema de la carencia monetaria, por lo tanto no se le daban estos servicios, «... en esta tierra nueva que los naturales della no tienen tanta distinción para entender que lo susodicho es limosna... muchos por ser pobres...el sacristan no quiere tocar campana por el difunto hasta que le paguen primero" (A.G.I., Quito, 82, N.6/1/1.Recto).

En este sentido, se comprende, que era mayor el perjuicio para la iglesia que para la persona difunta, que comprendía la muerte, y sus rituales post mortem ajenos a las tasas; y menos para su salvación. Eran conceptos, como se verá, ajenos a la percepción nativa.

Hay autores, como por ejemplo Polo de Ondegardo, que enumeran una serie de características que determinan porque los métodos y formas de evangelización no expandieron la fe cristiana. Para éste, el principal problema ${ }^{8}$ fue el total desconocimiento, desde un principio de la conquista, de los ritos y costumbres de los naturales. Según el autor la justicia se podría llevar a cabo bajo entendimiento, al igual que la expansión de los evangelios, si se conocía la cultura pre-colonial del Perú, sin provocarles el daño que las autoridades, tanto civiles como espirituales, les estaban causando. La opinión de P. Ondegardo, fue utilizada posteriormente, por José de Acosta, que resume así sus palabras:

compromisos, sus tratos, sus fechas indicadas por años, hacen pasar tres ańos y empieza a pasar y empieza a molestar» (Trabajo de campo, Potosí, Bolivia, 2006). El hombre andino adquiría un compromiso de reciprocidad con su entorno, la salud, el equilibrio, se percibían como la falta de algún miembro de la comunidad, como el olvido de su cumplimiento dentro de la comunidad. Si se olvidaba la reciprocidad se introducía la enfermedad: las malas cosechas, plagas, mala salud, etc.

8 Reflejado en la compilación que editó Historia 16 titulada El mundo de los Incas, o en los manuscritos que se pueden consultar como por ejemplo, Manuscrito 3169, MSS.MICRO/2156. Papeles varios sobre los indios incas, BNM, 37-61.
[...] que por tres causas le parecía haberse promovido poco el evangelio entre los indios después de tanto tiempo. Primero por los pésimos ejemplos de nuestros hombres...cuando antes de oír a los que les enseńaban el bien, veían primero a los que hacían el mal. Segundo por que los predicadores no habían puesto ningún empeño en conocer y extirpar los errores de los indios. Como a papagayos y urracas les enseñan solamente nuestras costumbres y sin convencerles ni explicárselo... Finalmente, por apenas haberse comenzado tarde a mirar por los intereses políticos y la administración de los indios...» (Acosta, 2008: 39).

Durante las campañas de evangelización, como podemos observar, la fe católica fue difícil de expandir debido a ciertas fronteras; en unos casos frágiles, en otros inquebrantables. Fronteras, conceptuales, como puede ser el concepto de «pecado», fronteras económicas, pagar por la salvación del alma, regionales, desubicación de la poblaciones, de comunicación, desconocimiento de la lenguas nativas, fronteras de la muerte, la negación.

\section{La muerte en la región centro andina precolonial}

Sobre la muerte, los rituales post mortem, encontramos trabajos de antropología muy buenos, pero un panorama del pasado es, en la mayoría de los casos, escueto y repetitivo?. Hace años realizamos un estudio e identificados la geografía del inframundo, su fauna y su flora. Este conocimiento, que resumiremos, ayuda a comprender cómo se entendía la muerte, cuál era el destino o destinos del difunto, cómo se moría y lo más importante, ¿qué se entiende por muerte? Esta pregunta, inevitablemente nos remite al concepto de vida. En el mundo prehispánico digamos que la vida se percibe como una serie de secuencias que articulan, de alguna manera, el ser que nace. Posteriormente, con el tiempo, debido a una enfermedad, un accidente, el ser pierde está completa formación que le distingue, y una parte de las cualidades que formaron la gran y completa articulación primigenia, intangible, una sustancia anímica, normalmente relacionada con la cabeza, el camac, viaja al mundo de los muertos para llegar a su destino.

9 Se recomienda el trabajo recopilatorio de Olinda Celestino sobre evangelización, idolatría, etc. (Celestino 1997 y 1998). 
¿Cuándo ocurre está articulación que compone al ser en su totalidad? En el día de nacimiento, el espacio tiempo imprime una serie de cualidades tangibles y no tangibles que determinan a ese individuo: por un lado un cuerpo material, compuesto por sustancia sagrada, y una parte no visible, lo que nosotros llamamos geometría anímica. Este acoplamiento material y no material, y el fluido espacio- temporal, determinan su vida y su muerte. El individuo, cuando nacía, era un ser temporal, es decir, tenía los mismos ciclos naturales que dominan la vida de los seres que habitan el Kay Pacha (García Escudero, 2012). A su vez, la muerte convertía al individuo en un ser atemporal. En este caso, no podemos hablar de muerte, sino de desarticulación de una pre-composición, para un posterior acceso de la geometría espacio-temporal: al hurin pacha o Mundo de los Muertos. Cabe destacar, que la geometría espacial, no son lugares estancos, como venimos diciendo hace tiempo, sino desplazamientos de espacio- tiempo accesibles y sin fronteras. Este es otro aspecto muy importante, el entorno no tiene fronteras, es movible y se relaciona con entidades sagradas. Por lo tanto, no se puede decir que tu alma no subirá a bajará si pagas, por ejemplo, sino que hay toda una complejidad entorno al concepto de nacimiento, su vinculación con la muerte pre y post estructuras materiales e intangibles.

El concepto de muerte, como se puede observar, no es similar al de los evangelios. Hemos reflexionado sobre la idea de lo difícil que podría ser para un párroco de indios comprender que el color puede ahuyentar la muerte, o que la muerte pueda tener una compañera. Es decir, un matrimonio del inframundo. $\mathrm{O}$ que en determinadas fechas y horas el inframundo puede tener acceso e invadir el mundo terrestre. Un sinfín de apreciaciones ligadas a la Muerte, como termino general, no perceptibles a lo tangible, sino a similitudes etéreas, sin cuerpo, sin materia, pero que afectan a la comprensión de ésta y la vida en el antiguo Perú. Estos planteamientos nos hicieron observar los problemas que nos impedían mejorar los análisis, así, intentar hacer estudios globales, nos llevaron a construir, plantear una posible solución. La solución está en analizar las realidades cuantitativas y las cualitativas del objeto de análisis: lo que hemos denominado estudio de la dimensionalidad (García Escudero, 2017). Este método ha permitido entender muchos aspectos de la cosmovisión

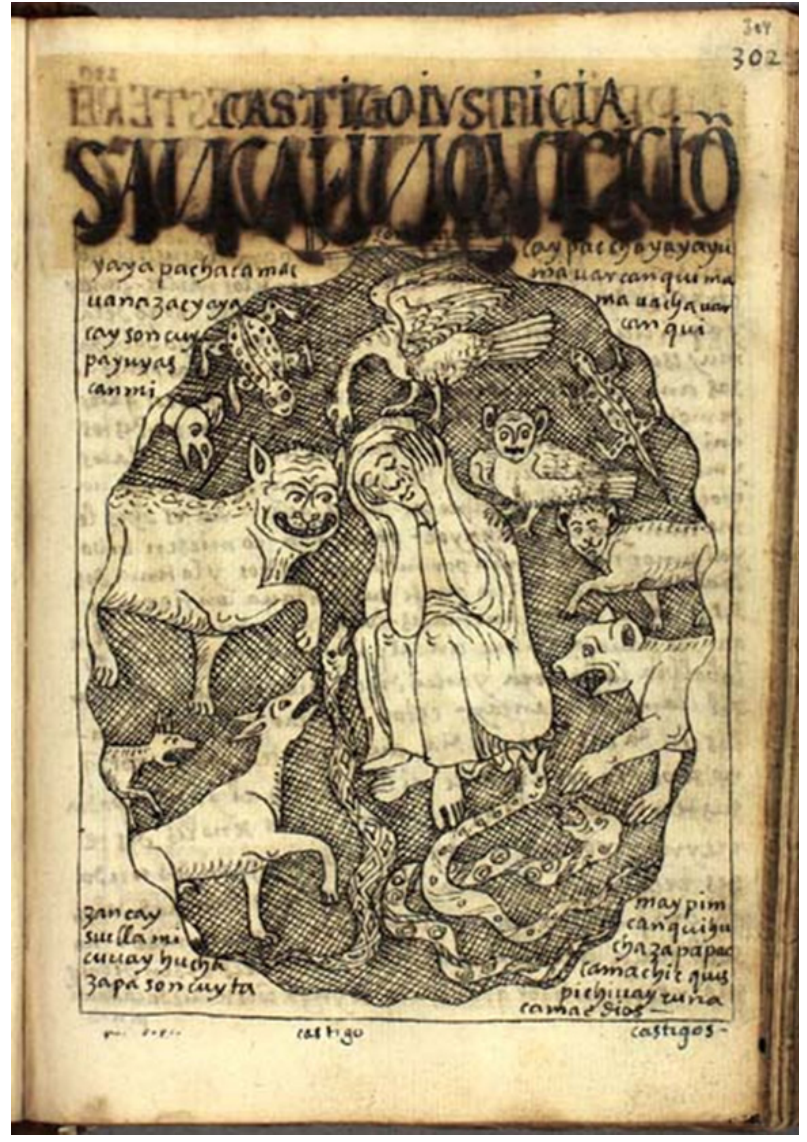

FIGURA 1. CASTIGO, IVSTICIA, SANCAI (cárcel perpetua), según, Guaman Poma de Ayala, digitalización de GKS 2232, 40, en 2000, Det Kongelige Bibliotek. Página 302.

inca. La muerte tiene una dimensión material, ligada al ritual entorno al cuerpo, por ejemplo, pero, también tienen una dimensión no tangible, que complementa el estudio de ésta, como pude ser el estudio de la causa de esa muerte, una causa no tangible, como sufrir un espanto o ser impregnado por hedor, y la entidad que tiene que realizar el viaje por el inframundo, la naturaleza y la muerte, etc. Durante la colonia los evangelizadores relacionaron el mundo de los muertos, lo que ellos entendían como tal, con la oscuridad y el Diablo. Tras el estudio de las fuentes y la aplicación de la dimensionadad, nos dimos cuenta que este aspecto, la Muerte y el "Diablo», fueron sumamente simplificadas durante la evangelización. Esa simplificación, en muchos casos para intentar facilitar la convivencia, produjo otras muchas en diferentes áreas socioculturales.

Las caras del diablo fueron relacionadas con los hechiceros y su trabajo (Figura 1). En la figura que 
hemos seleccionado, como se puede ver, hay uno de los hechiceros- demonios que chupan la sangre y provocan la muerte, y en la actualidad es muy común esta relación de muerte por extracción de sangre y su relación con un ser inframundano:

[...] una persona está bien y al día siguiente empieza enfermar, está totalmente pálida y cuando le revisan apenas hay nada, un puntito, una costrita y cuando ven ese puntito dicen lliquichiri, dicen que le han sacado toda su grasa, toda su sangre y le hacen preparar. Hay un señor que le ayuda y un vaso que vale cien bolivianos y cuando así no se hacen cuidar, entonces mueren. Esa gente cuando esta lliquichara se vuelve flaco y se muere... (Trabajo de campo, Tuysuri, Tinquypaya, Potosí, Bolivia, septiembre, 2006).

Las crónicas hablan de una segunda vida tras la muerte similar a la subsistida en el plano terreno. Esta «segunda vida», se realizaba junto a los difuntos de la familia, y junto a los familiares del plano terreno: no se diferenciaba una separación del individuo, la comunidad y la familia. Este aspecto es de suma importancia, pues, el difunto está presente en reuniones, protege a la familia, etc.

El inframundo era el espacio tiempo que antaño, como nos muestran los mitos cosmogónicos, gobernó el plano terrestre o kay pacha (plano intermedio) Éste fue vencido y desplazado a otra región (Ávila 1975:51 y sig). Así, el difunto se desplaza a otro plano, pero tiene un destino ligado a su nacimiento, un espacio-tiempo concreto, y a su vida en comunidad.

De esta geometría anímica que posee el hombre, la más poderosa, tras el análisis de los textos, es el camac: es poderosa, enérgica, valiente, y fuerte, entre otras muchas cosas. Se relaciona con la fuerza vital que ha sido donada por un agente celeste, dota al individuo atemporalidad que, tras la muerte, realiza el viaje inframundano. Era destino e iluminaba al difunto en el largo y oscuro trayecto inframundano; con la ayuda de la comunidad. Ésta, los primeros 5 días de su salida del cuerpo, o muerte, recorría los lugares que en la vida había recorrido el difunto ${ }^{10}$. Pero, esta es un alma, sabemos que tenían más, esto,

10 Consultar bibliografía: García Escudero, M.C. (2009). «El mundo de los muertos en la cosmovisión centro andina», en Gaceta de Antropología, [en linea] 2009, 25:25-51 Disponible en: http://www. ugr.es/-pwlac/G25_51Carmen_Garcia_Escudero.html. como veremos, acarreó mucha confusión durante la colonia. Es más, se podía, y se puede como observamos en los trabajos de campo, vivir sin una de las entidades anímicas: esto es causa de una enfermedad. Es decir, la salvación del alma es compleja de ubicar con los evangelios, debido, principalmente, a esta articulación que estamos viendo.

\section{Las fronteras y las reacciones}

Repercusiones internas, ¿cómo salvar el alma?, ¿cómo cambiar la muerte?, son dos cuestiones principales para comprender «las fronteras de la muerte». Hemos situado las fronteras determinándolas en el momento de activar las medidas urgentes que propusieron los evangelizadores: los «actos urgentes» para la población pagana (recuérdese página 4). Entre estos dos ejes veremos cómo se compone un interesante juego de espejos que ayuda a comprender aspectos de la muerte pre y post colonial. Si nos fijamos, la composición del hombre involucraba, a mi forma de analizar, dos dimensiones, ambas indivisibles, por un lado la composición material, adjunta al espaciotiempo en el que se nacía, y que le imprimía una serie de cualidades no tangibles, pero definitorias para su vida-muerte. Un cuerpo material y divino (en los textos podemos apreciar que se relaciona en los mitos de origen con el sacrificio de una entidad divina), y por otro lado una geometría anímica espacial plural; como hemos descrito. Esto quiere decir, que la salvación del alma, no se comprendía en su totalidad, porque partimos de una percepción plural de entidades anímicas, y, como hemos comentado antes, se podía vivir si alguna de ellas. Todas éstas almas eran importantes, ninguna de ellas significativa para la salvación.

Para la cosmovisión precolonial había una geometría espacial (García Escudero, 2015), una geometría vertical y horizontal, cada una de ellas con ubicaciones, flora, fauna, etc. Esta geometría, la ubicación del hombre en ella y el destino de éste, tras la articulación del ser en su nacimiento, nos indican dos aspectos importantes. El primero de ellos, es la pluralidad del ser, la segunda, es que en el nacimiento tenemos la primera presentación del ser al inframundo, cuando era enterrada la placenta. Así, el destino del difunto dependía de su interrelación con la comunidad, de su ubicación espacial que le determinaba en su en- 
torno, y con su percepción de deberes con sus seres divinos, huacas, dioses etc. Por ejemplo, nacer, en el diccionario de González Holguín, se relaciona con Pacarini yurini: salir algo a la luz (González, 1952: 367 y 241). Nacer es similar a salir del inframundo, y cada uno de los ayllus tenían su pacarina de nacimiento, que era la pacarina por la cual se regresaba tras la muerte: al vientre de la tierra. Es decir, la vida y la muerte están en continua comunicación. Sobre el tema Pablo José de Arriaga observó lo siguiente: «...de donde descienden... una de las causas porque rehúsan tanto la reducción de sus pueblos... y la principal razón que dan es que está allí su pacarina..." (Arriaga, 1968: 2002). En un manuscrito del Archivo Histórico de la Paz, aparece que: «los indios serranos no pueden tener tierras enballes calientes y nos pidio y suplico... no fuesen desposeídos de sus tierras porque están aquí desde sus antepasados...» (La Plata, 30, IV.1590. ALP. EC. C1.E.29. AHP). Entendemos que para el hombre andino hallarse cerca del lugar del cual había surgido, su pacarina, era vital para conocer el lugar por el cual debía comenzar su peregrinación inframundana. De esta manera el desplazamiento territorial no se reducía a una simple negación de las poblaciones indígenas por un traslado, sino que con estos movimientos poblacionales se impedía que éstas tuviesen paso al inicio de su camino por el inframundo andino y su acercamiento con los antepasados, con el presente y el bien estar comunal (sin mencionar las repercusiones económicas que había por el reparto de tierras, sus cuidados, etc.). Para comprender, además, este pensamiento cabe mencionar que no se puede pensar en un tiempo lineal; como hemos descrito en un reciente artículo; esta apreciación es compleja, pero determinada la vida y muerte de un individuo en comunidad (García Escudero, 2017).

Tanto en el texto de Dioses y hombres de la provincia de Huarochirí como en los escritos de Guamán Poma de Ayala, Nueva corónica y buen gobierno (1987), son especificadas aquellas acciones que involucraban castigos en el período precolonial, una de éstas fue el olvido de sus divinidades y huacas regionales de cada ayllu (Figura 2). El olvido era similar a la destrucción de su entorno, a la no relación con su comunidad; similar a la desaparición de la cultura y todo lo que conlleva esta percepción. En este caso, la evangelización obligaba a no recordar, a olvidar aquello que les unía con sus antepasados. El olvido,

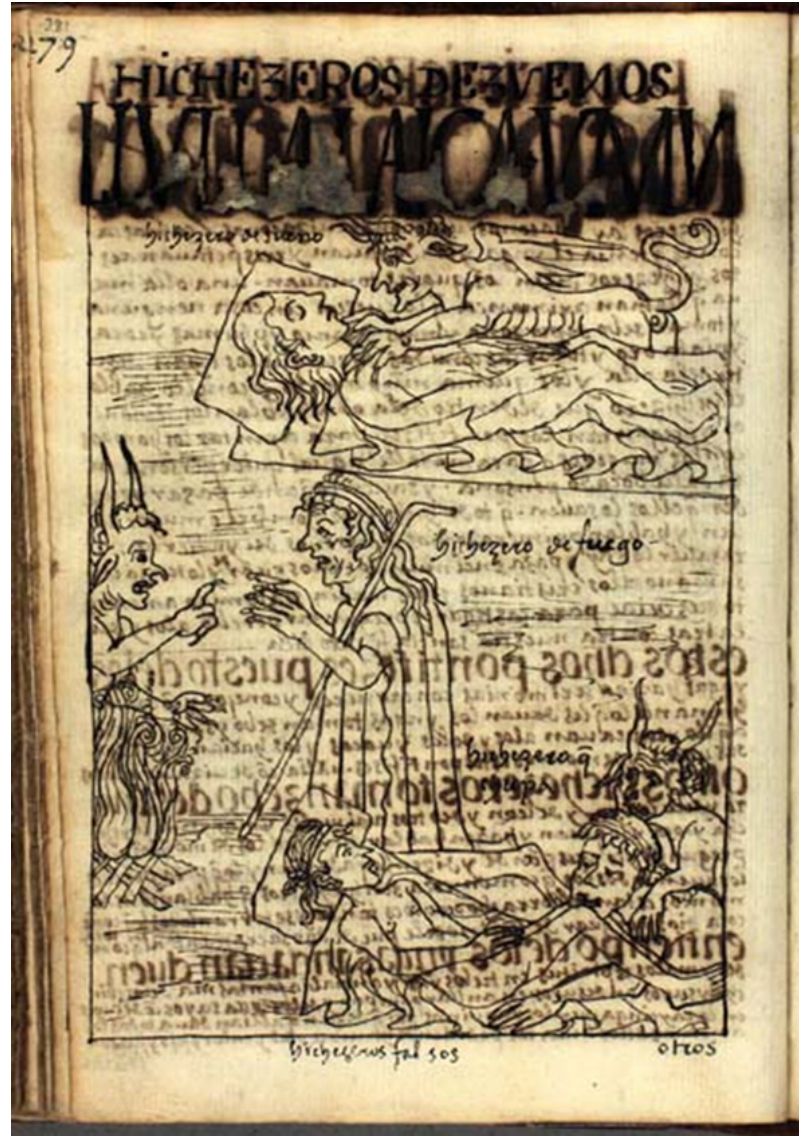

FIGURA 2. Hechiceros y brujos mentirosos/ hichezero de sueño / hichezero de fuego / hichezero que chupa / hicheseros falsossegún, Guamán Poma de Ayala, digitalización de GKS 2232, 40, en 2000,

Det Kongelige Bibliotek. Página 279.

fue introducido durante las campañas de idolatría, mediante, recuérdese, la separación poblacional. Por ejemplo, en las campańas de idolatría se buscaba si la memoria y la idolatría seguían vigentes. En la Gramática Muisca ${ }^{11}$ encontramos los mandamientos que el doctrinero tiene que observar:

¿Has creido en sueños?

¿Quando llora la tórtola o ahulla el perro, has dicho, que es para suceder algún mal?

¿Mascas tabaco?

¿Has usado de yervas o hechizos?

¿Has muerto alguien con yervas?

¿Has hecho algún aborto?

¿Has descubierto el secreto natural? (Lugo, 1619:298)

11 Cultura no inca pero sí andina, pero, recuérdese, que implicó cierta influencia por las dimensiones y formas de expansión del Tahuantinsuyu. 
Estas preguntas, como se puede observar, están encaminadas a ver qué hay de sus antiguas creencias. El sueño, es una pregunta muy interesante, por varias razones. La primera de ellas, es que tanto en el pasado como en el presente, el sueño es una forma de contacto con los antepasados y encamina la vida de la comunidad: es un medio de comunicación, y una muerte transitoria «... pues la muerte lo a de llegar como agora los anochesse, sueño ymajen de muerte..." (Mss.3169:fol.145, p14.r. B.N.M). El espíritu del cadáver, explican Romero, Urteaga y, protegía, a modo de tótem familiar, de las enfermedades y daba consejos entre sueños (Villagomez, Urteaga, \& Romero, 1919:93). El Moscoc, por ejemplo, era el «adivino» que realiza sus predicciones mediante el sueño. Utilizaba la ropa del afectado para dormir sobre ella y adivinar aquello que le había sido preguntado (Arriaga, 1968: 206). Estos «hechiceros» usaban ciertas prendas, que son llamadas sombras pues "contiene» la sombra o doble espiritual de la persona (Polia, 1995: 40). En sueños, por ejemplo, habían recibido el oficio la parteras, asistiendo a éstos o practicando abortos a las indias. En la actualidad el sueño tiene la misma importancia. En el trabajo de campo que realizamos en Potosí, la maestra del pueblo de Tuysuri, Patricia Fuertes nos explicaba que su novio la dijo:

[...] cuando algo malo te va a pasar días antes te sueñas. He soñado feo he visto a mi hermano $\mathrm{X}$ viendo coca, $\mathrm{y}$ he visto pieza por pieza del auto, vas a tener cuidado de que pase algo, he visto feo vas a tener cuidado...el Diego nos estábamos trasladado aquí y el bus ha atropellado a una persona. Algún problema va a ver, coca es pena, cuando uno está hilando la lana de la oveja, también es pena... (Trabajo de campo, Potosí, Bolivia. 2006).

El difunto se percibía como el árbol que introducía la raíz en el inframundo, se alimentaba de las entrañas de la tierra, para donar posteriormente los frutos que alimentaban a la comunidad. Los diccionarios quechuas y aymarás traducen mallqui como difunto y como árbol. Pablo José de Arriaga escribió que los cuerpos de los difuntos en los llanos se llamaban munaos y en la sierra mallquis (Arriaga,1968: 13). El difunto auxilia a la comunidad e interviene en los ciclos agrícolas, vela por la fertilidad de los campos.

Otro aspecto muy importante, y que aparece en las crónicas y textos coloniales, es que la muerte es un castigo de las divinidades, digamos que para ellos la muerte sobrepasaba la dimensión puramente biológica. Y, la vida, los rituales, habían sido establecidos por las divinidades que habían "construido», de alguna manera, el espacio- tiempo en el que vivía el hombre. Estos espacios y el individuo eran habitados de formas diferentes: por el cuerpo, por una parte del ser, el alma, por el hedor, etc. Por eso es tan importante saber la relación de la "construcción" del hombre, y esa de-construcción: la vida y la muerte son percepciones mucho más complejas que aspectos conceptuales.

El Demonio se trasformó en el actor principal para las visitas para buscar la idolatría y sus múltiples facetas,»...tienen unos santuarios e ydolos y otros y hazen usandolos ritos y areytos diabolicos antiguos en ofensa de nuestro señor dios ofreciendo oro, piedras y mantas e otras cosas al demonio...» (A.G.N, D.28/614.). Así, se simplificó el concepto de seres del inframundo y se omitió el matrimonio del inframundo; tan importante hasta nuestros días. En casi todas las regiones quechua de Potosí, nos indicó durante el trabajo de campo el médico tradicional Alberto Camaqui, las formas que pueblan el cosmos poseen un aspecto femenino y otro masculino. En las comunidades se concibe que esta unión es la que crea la vida, y que sin ambos sexos la vida no se regenera. Para éstos, supay es un espíritu masculino del inframundo, cuyo lado femenino es la china supay. Al respecto el médico tradicional nos explicó que: «[...] en el mundo andino se utilizan siempre que son parejas, hay supay china. Todo son parejas, todo funciona con parejas, hasta las piedritas, siempre existe este género, lo masculino y lo femenino...» (Trabajo de campo Potosí, Bolivia. 2006).

Sobre el bautismo, en la cosmovisión andina, podemos decir que hay una primera etapa en la cual se relaciona la creación con el agua, pero, lo importante en el nacimiento, no era tanto el bautismo, sino enterrar, en la zona fértil del inframundo, la placenta del recién nacido. Era una primera presentación de éste a una región que después tendría que conocer. Era una entidad anímica. Al ser bautizados, los actos en torno a la vida-muerte, como rituales a las huacas de nacimiento, construcción de la cuna, o los rituales de acompańamiento y seguimiento al difunto hacia su pacarina fueron prohibidos. ¿Qué consecuencias se aprecián? que los familiares sacaban de los enterramientos cristianos a sus difuntos porque éstos impedían realizar el viaje por el inframundo, no tendrían 
o podrían llegar a su destino. Se quedarían como espantos: atrapados. Es más, dejarían de ser difuntos integrados en la comunidad y su desarrollo. Durante la extirpación de las idolatrías destacan la localización, similar en cada región del Tahuantinsuyu, de los «objetos relacionados con la muerte y, en particular, los cuerpos de los difuntos que siguen recibiendo atención después de su fallecimiento» (Kaulicke 2016: 22). Los familiares robaban por las noches a sus difuntos, los desenterraban, para llevarlos junto a sus antepasados acompañados de sus familiares y amigos. Además, realizaban las ceremonias que el difunto se merecía: cánticos, bailes funerarios y el recuerdo a través de la tradición oral. Entendemos que todos estos hechos se debieron, entre otras muchas cosas, a que para la cultura prehispánica del Perú la sepultura de sus difuntos debía realizarse junto a los cuerpos de sus antepasados, y a través de un ritual que introducía al difunto por su pacarina hacia el camino del inframundo. Además, fue una costumbre primordial en una sociedad donde la vida se había construido en colectividad. Por lo tanto, la muerte la sufrían acompañados de sus familiares más cercanos, y la disfrutaban en las sepulturas de sus ancestros:

[...] en muchas partes y creo que es en todas las que an podido, an sacado los cuerpos de sus difuntos de las Yglesias, y lleuándolos al campo, a sus Machays, que son las sepulturas de sus antepasados, y la causa que dan de sacallos de la Iglesia, es como ellos dizen Cuyaspa, por el amor que les tienen. En conclusión para hazer concepto del miserable estado en que están, y de la necesidad extrema que tienen de remedio, y la facilidad y gusto con que le admiten, no es menester otro testimonio más que ver vn día de las exhibiciones, que es quando todos juntos traen todos los instrumentos de su idolatría. Parece vn día de Iuicio, están repartidos en la placa por Ayllos, y parcialidades, tienen consigo los cuerpos secos, y enteros de sus antepasados, que en los llanos llaman Munaos, y en la sierra Malquis, y los cuerpos que han sacado de la Iglesia, que parece que los vivos, y los muertos vienen a Iuicio, traen todas sus Huacas particulares y los ministros mayores las Huacas comunes, a quien servían los vnos y los otros con las ofrendas q' tenían para ellas, los vestidos con q'hazían las fiestas, los plumajes con que se adornaban, las ollas, cántaros, y vasos de diversas maneras para hazer la chicha, y para bevella, y ofrecella a las Huacas (Arriaga, 1968:13 y sig)
Para las poblaciones nativas, el bautismo ${ }^{12}$ fue relacionado con la puesta de nombre, pero, la puesta de nombre era un ritual mucho más complejo; era una entidad anímica adscrita al ser que nacía. Al respecto en el diccionario de Fray Diego González Holguín hallamos los siguientes vocablos: Suti: Nombre generalmente (González Holguín, 1952: 218), Sutiyachini: Bautizarle, o ponerle nombre el padre (González, 1952: 218); Sutiyacun, o sutiyachicun: Bautizarse, o ponerse nombre (González, 1952: 218); Sutiyok sutiyachiscca: Bautizado o puesto nombre (González, 1952: 218). Antes de la colonia el nombre se relacionada con el espacio tiempo en el que se nacía y se cambiaba según se iba creciendo. Al respecto Cieza de León escribía lo siguiente:

[...] una cosa noté en el tiempo que estuve en estos reinos del Perú, y es que en la mayor parte de sus provincias se usó poner nombres a los niños cuando tenían quince o veinte dias, y les duraba hasta ser de diez o doce ańos, y desde tiempo, y algunos de menos, tornan a recibir otros nombres, habiendo primero en cierto día, que está establecido para semejantes casos, juntándose la mayor parte de los parientes y amigos del padre, adonde bailan a su usanza y beben, que es su mayor fiesta, y después de ser pasado el regocijo, uno de ellos, el más anciano y estimado, tresquila ala mozo o moza que ha de recibir nombre y le corta las uñas, las cuales, con los cabellos, guardan con gran cuidado. Los nombres que les ponen y ellos usan son nombres de pueblos y de aves, o hierbas o pescado... nombres de sus padres o abuelos (Cieza de León, 2005: 260).

Podríamos decir que el nombre no era una simple denominación, sino una fuente de información sobre el espacio-tiempo en el cual se había efectuado la creación del propio individuo, lo caracterizaba. Esto implicó que durante la extirpación de la idolatría se supiesen localizar a los hechiceros por su nombre.

En cuanto al destino es un aspecto muy importante, recuérdese, que en la cosmovisión inca el destino de los difuntos está ligado a la vida en comunidad, a la reciprocidad. Tenían que ayudar a su ayllu, no saltar las reglas establecidas por el culto regional y

12 Se recomienda la lectura siguiente: García Escudero, M.C. (2009). "El mundo de los muertos en la cosmovisión centro andina», en Gaceta de Antropología, [en línea] 2009, 25:25-51 Disponible en: http://www.ugr.es/ pwlac/G25_51Carmen_Garcia_Escudero.html. 
estatal del Inca, para tener un camino lo más fácil posible. Este destino, además, para un campesino, por ejemplo, era llevar una vida similar con sus antepasados. Otros destinos fueron los de los infantes, el Inca o los guerreros.

La muerte se relaciona con un acto de deconstrucción de una creación determinada: el espacio tiempo relacionado con el nacimiento ${ }^{13}$. El hombre, se componía de un aspecto material, el cuerpo, y la geografía anímica plural; como hemos mencionado. Entonces, el paradigma fue como salvar un alma, cuando percibían varias en el individuo, y cuál se podía salvar mediante pagos a la iglesia, pero, lo más importan te, fuera de la reciprocidad precolonial y sus implicaciones socio-culturales. Esta reciprocidad, no se podía llevar a cabo por varios aspectos, uno de ellos fue la separación geográfica del individuo y su entorno, no podían ir a su pacarina, a su ubicación geográfica de nacimiento. Por otro lado, como método de evangelización, recuérdese, que en las comunidades se separaba a los individuos; para una mejor expansión del evangelio. Estas separaciones repercutieron en una difícil realización de los rituales pre y post mortem. La muerte se trasformaba, pero, la muerte en el mundo precolonial, en la región centro andina, no existía como tal, con la evangelización, y la simplificación y conceptualización de la cultura andina, se estaba desarrollando un declive de la sociedad andina y de su desarrollo óptimo.

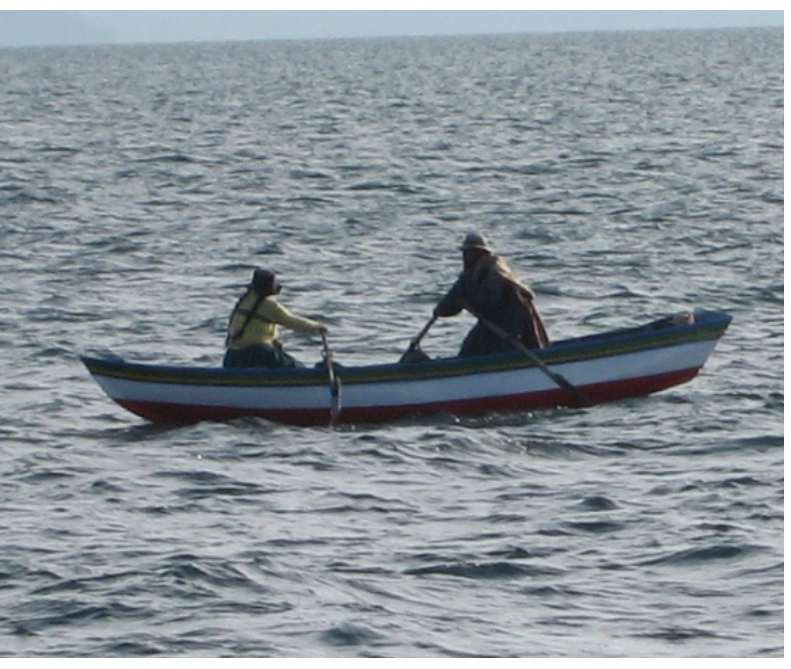

13 Se recomienda la siguiente lectura: García Escudero, M.C, (2017). «Introducción al estudio de la «dimensionalidad» y su aplicación al concepto pacha en el antiguo Perú», en Annales del Museo de América, XXIV, Madrid.
Podríamos concluir que la muerte, como nosotros la entendemos, no existió en los Andes, fue, y es, el lugar donde nunca se muere, hay una trasformación y movimiento por la geografía espacio-temporal: «le encomendó a su ser que después de muerto en llegando a la otra parte de el Mar, sembrase mucho maíz y hiçiese casa, para que muertos él y su madre fuesen a vivir con él» (De la Cruz. 1653:p.45.v.Mss.2450). Con estas palabras terminamos el artículo, no hay mejor definición que la descrita en el manuscrito y más hermoso pensamiento. (Figura 3).

\section{Bibliografía}

Acosta (2008 [1509]). Historia Natural y Moral de las Indias. (F. d. Díaz, Ed.) Madrid: Cyan, proyectos y producciones editoriales, SA.

Arriaga, P. (1968 [1621]). Extirpación de la idolatría del Perú. Madrid, España: BAE.

Ávila, F. (1604 [1598]). Dioses y hombres de Huarochirí. Lima, Perú: Manuscrito, Biblioteca Nacional de España.

Ávila, F. d. (1975). Dioses y hombres de Huarochirí. Mexico, México: Siglo XXI editores.

Celestino, O. (1997). Transformaciones religiosas en los Andes peruanos. 1. Ciclos míticos y rituales. (P. Gómez, Ed.) Gaceta de Antropología, 13(06), 1-19.

Celestino, O. (1998). Transformaciones religiosas en los Andes peruanos. 2. Evangelizaciones. (P. Gómez, Ed.) Gaceta de Antropología, 14(05), 1-22.

Cieza de León, P. (2005[1553]). Crónicas del Perú. El señorío de los incas. Caracas, Venezuela: Fundación biblioteca Ayacucho.

García Escudero, M. d. (2012). Estudio sobre el nacimiento y la composición anímica del hombre en la cosmovisión prehispánica centro-andina. Anales del Museo de América (XIX).

García Escudero, M. d. (2015). Análisis de la estructura del Universo en las fuentes escritas y su perspectiva dimensional: Incas versus quechuas. Revista Hombre y Desierto (18).

García Escudero, M. d. (2017). Introducción al estudio de la «dimensionalidad» y su aplicación al concepto pacha en el antiguo Perú. Annales del Museo de América (XXIV). 
González Holguín, F. (1952). Vocabulario de la lengua general de todo el Perú llamada lengua Qquichua o del Inca. Lima, Perú: Instituto de Historia.

Guaman Poma de Ayala, F. (1987 [1613]). Nueva crónica y buen gobierno. Madrid, España: Historia 16.

Kaulicke, P. (2016). Memoría y muerte en el antiguo Perú. Lima, Perú: Pontificia Universidad Católica del Perú, Fondo Editorial.

LisI, L. F. (1990). El II Concilio Limense y la aculturación de los indígenas sudamericanos. 23. Salamanca, España: Universidad de Salamanca.

Lugo, F. B. (1619). Gramtica en la lengua general del nuevo reino, llamado mosca. (M. Bernardino de Guzmán, Ed.) Santa Fe, Bogotá, Colombia.

Millones, L. (1989). Mesianismo e idolatría en los Andes centrales. Buenos Aires: Cuader-nos Simón Rodríguez, 15, ed. Fundación Simón Rodríguez.

Millones, L. (1997). El rastro de la fe, doce ensayos sobre religiosidad andina. Sevilla: Universidad Pablo de Olavide y Fundación El Monte.

Murúa, F. M. (2001). Historia general del Perú. Madrid, España: Dastín, Crónicas de América.

Peña de Montenegro, A. (1995). Itinerario para párrocos de Indios (Corpus Hispanorum de Pace ed., Vol. I y II. Madrid, España: CSIC.

Platt, T. (2002). El feto agresivo.Parto, formación de la persona y mito-historia en los Andes. Estudios Atacameños, 127-155.

Polia, M. (1995). La mesa curanderil y la cosmología andina. Antropológica(13), 23-53.

Ricardo, A. (1584). Arte, Vocabulario en la lengua general del Perú llamada Quichua, y en la lengua española. Lima, Perú.

Santillán, H. de (1968). Relación del origen descendencia, politica y gobierno de los incas, Madrid, en Esteve Barba, Crónicas peruanas de interés indígena, ed. BAE.

Villagomez, P., Urteaga, H., \& Romero, C. (1919). Exortaciones e instrución acerca de las idolatrías de los indios del Arzobispado de Lima. Lima: Sanmartí.

\section{Manuscritos}

Manuscrito 3169, MSS.MICRO/2156. Papeles varios sobre los indios incas, Huarochiris y otras antigüedades del Perú:

- Relación de las fábulas y ritos de los Incas, hecha por Cristóbal de Molina, cura de la parroquia de Nuestra
Señora de Los Remedios del Hospital de los naturales de la ciudad del Cuzco, dirigida al Reverendísimo Señor Obispo del Artaum... (h. 2-36v).

- Tratado de un cartapacio, a manera de borrador que quedó en los papeles del Licenciado Polo de Ondegardo, acerca del Linaje de los Incas y como conquistaron [Perú] (h. 37-61).

- Manuscrito quechua de Huarochirí: Runa yno niscap Machoncuna naripapacha quill casta yachan mancarca Chayca... [Capítulo 1-35. Títulos de los 6 primeros capítulos y notas marginales en espańol] (h. 64-105v y las h. 106-107, mal encuadernadas, pertenecen al final del capítulo 11 y comienzos del 12).

- Tratado y relación de los errores, falsos dioses y otras supersticiones y ritos diabólicos, en que vivian antiguamente los indios de las provincias de Huaracheri, Mama y Challa, $y$ hoy también viven engañados, con gran perdición de sus almas; recogido por el Dr. Francisco de Ávila, presbítero (cura de la dicha provincia de Huacheri y vicario de las tres arriba dichas). Año de 1608 (h. 115-129) [Incompleto al final, capítulos 1-7].

- Relación de las antigüedades de este Reino del Perú, por Juan de Santa Cruz Pachacuti Yamqui Salcamaygua; incluye dibujos a pluma (h. 131-174).

- De la Cruz, F. Laureano. Descripción del Perú o llamado América en el mar del sur, llamada imperio de los reynos del Perú. Descripción, conquista y evangelización, 1653. Manuscrito $\mathrm{n}^{\circ} 2450$.

- Relación del origen de los yngas del Perú, sus costumbres en el gobierno, ritos y ceremonias que usavan en tiempo de su gentilidad. Manuscrito R/62674.

- Bautista de Salazar, Antonio, Libro de la descripción del Perú, discurso de goviernos de los vissorreies y gobernadores del, grandezas de la ciudad de los reises, calidad de las demas y de los corregimientos, con las rentas que el rei nuestro señor tiene y otras cosas. 1596. Manuscrito 2010.

- Archivo Histórico, La Paz, Bolivia.

La Plata, 30, IV.1590. ALP. EC. C1.E.29.

Diversos-Colecciones, 25N.10.

- Archivo General de Indias, España.

A.G.I, Patronato190, R.42 /1/1.

A.G.I., Quito, 82, N.6/1/1.Recto.

- Archivo General de la Nación, Colombia.

A.G.N, D.28/614

A.G.N, D.11/ hoja 705. Recto. 